SCADidoc

International Journal of Dentistry and Oral Science (IJDOS) ISSN: $2377-8075$

\title{
Prevalence Of Preventive Dental Treatment Preferred By Medically Compromised Children In A Private Dental Institution-A Retrospective Study
}

Research Article

Nurul Afiqah Amani Binti Zaaba ${ }^{1}$, Jessy $P^{2 *}$, K. K. Shantha Sundari ${ }^{3}$, Deepa $G^{4}$

${ }^{1}$ Saveetha Dental College and Hospital, Saveetha Institute of Medical and Technical Sciences Saveetha University, Chennai, India.

${ }^{2}$ Senior Lecturer, Department of Pedodontics, Saveetha Dental College and Hospital, Saveetha institute of medical and technical sciences (SIMATS)

Saveetha University, Chennai, India.

${ }^{3}$ Professor, Department of Orthodontics, Saveetha Dental College and Hospital Saveetha institute of medical and technical sciences Saveetha

University, Chennai, India.

${ }^{4}$ Professor, Department of Pedodontics, Saveetha Dental College and Hospital, Saveetha institute of medical and technical sciences (SIMATS)

Saveetha University, Chennai, India.

Abstract

Background: Medically compromised children and special children are categorized as a high risk group to develop oral disease. Preventive measures are necessary in order to control or prevent any oral complications.

Aim: The aim of this study is to assess the prevalence of preventive dental treatment preferred by medically compromised children.

Materials and Methods: A total of 182 documented medical records of medically compromised children that fulfilled the inclusion and exclusion criteria were collected for this retrospective cross sectional study. Demographic information, medical history, and recommended preventive dental treatments of the patients were collected. Results were analyzed with IBM SPSS version 23 to evaluate the acceptance and prevalence of preventive treatments by medically compromised children.

Results: The results showed that the prevalence of acceptance towards preventive dental treatment was $28.6 \%$, while the majority of the children did not undergo any preventive treatments $(71.4 \%)$. The children preference towards preventive treatment was higher among 7-9 years of age group (7.7\%) and higher preference was found among males (17.6\%). According to type of preventive treatments, the prevalence of preference towards pit and fissure sealants $(11 \%)$ was more compared to topical fluoride application (8.8\%).

Conclusion: Hence it can be concluded that the prevalence of medically compromised children preferring preventive dental treatment was relatively less. Most of the category of systemic diseases preferred very less preventive treatment except patients with nervous system disorder and the children preference towards preventive treatment was higher among 7-9 years of age group with boys being predominant. Pit and fissure sealant was the most preferred preventive treatment of choice than fluoride application.

Keywords: Medically Compromised Children; Preventive Dental Treatment; Special Children; Acceptance; Oral Health.

\section{Introduction}

Parents' behavior and attitudes will influence the oral health of their children [1], as it is important for speech, esthetics, and normal functions $[2,3]$. It is a serious issue of concern in paediatric dentistry $[4,5]$, as they are susceptible to develop higher risk of oral disease $[6,7]$. Bensouda Sana et al reported that dental caries mainly related to oral hygiene measures [6] with lack of awareness of parents on the children's dental treatments [8, 9]. Therefore, earlier diagnosis and preventive dental treatments will halt the progression of dental caries [10-14]. Hence, this study was done to study the parental acceptance of preventive treatment for medically compromised children and special children.

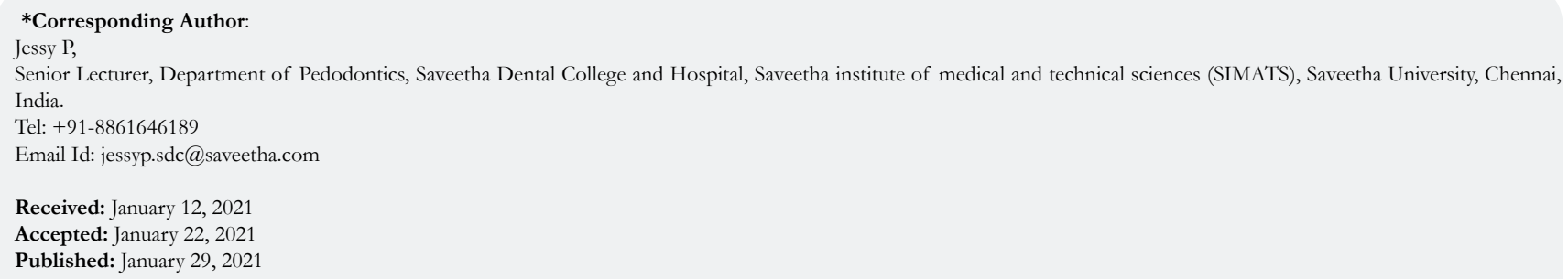

Citation: Nurul Afiqah Amani Binti Zaaba, Jessy P, K. K. Shantha Sundari, Deepa G. Prevalence Of Preventive Dental Treatment Preferred By Medically Compromised Children In A Private Dental Institution-A Retrospective Study. Int J Dentistry Oral Sci. 2021;08(01):1492-1498. doi: http://dx.doi.org/10.19070/2377-8075-21000298

Copyright: Jessy $\mathbf{P}^{\circ}$ 2021. This is an open-access article distributed under the terms of the Creative Commons Attribution License, which permits unrestricted use, distribution and reproduction in any medium, provided the original author and source are credited. 


\section{Materials and Methods}

\section{Study setting}

It is a university setting study, conducted in Saveetha Dental College and Hospitals. The pros of the study included the available data and similar ethnicity. Ethical clearance for this study was obtained from the Institutional Ethical Committee. Two examiners were involved in the study.

\section{Inclusion criteria}

- Children less than 18 years of age were included

- Medically compromised children and special children were only considered

- Patients with documented medical records were considered.

\section{Exclusion criteria}

- Healthy individuals without any medical illness were excluded. - Patients above 18 years of age were eliminated.

\section{Sampling}

It is a retrospective study. The data was collected from the patients' record of saveetha dental college. The data included in the study were from June 2019 to March 2020. 5000 consecutive case sheets were reviewed from which 182 medically compromised patient's case sheets were collected who had fulfilled the inclusion and exclusion criteria. Each child medical and dental records were reviewed and their associated photographs were taken into consideration. Telephonic cross verification was done by two reviewers. Collecting more data sources and including the data only from the institute were the measures taken to minimize the bias. The internal validity included randomization and blinding and defining the eligible criteria of the sample was the external validity.

\section{Data collection}

Data were collected from case sheets which included the demographic details, medical history, and recommended preventive dental treatments of the patients. Data was entered methodical manner in Excel and was imported to SPSS and variables were defined. Incomplete and censored data were excluded from the study.

\section{Analytics}

IBM SPSS version 23 was used for statistical analysis. Correlation analysis - Chi square test was used to compare the association between various preventive dental treatments and the medically compromised children. Descriptive analysis was used to describe the age and gender distribution of the study population. Independent variables were medically compromised children and special children and dependent variables were preventive dental treatments.

\section{Results}

Out of 182 patients, 59 (32.4\%) were female and $123(67.6 \%)$ were male. Among 182 patients, 52 children accepted the preventive dental treatment giving a prevalence of $28.6 \%$ and remaining didn't prefer treatment $71.4 \%$. The patients have had an age range of 1-18 years with mean age of 9.6. In this study, Figure 1 shows distribution of medically compromised children based on their medical history. The most frequently encountered medical condition category in this institute, was nervous system disorders $(26.9 \%)$, followed by others miscellaneous diseases $(20.3 \%)$, patient with specific needs $(13.7 \%)$, respiratory disorders $(11 \%)$, endocrine diseases $(7.7 \%)$, gastrointestinal diseases $(13 \%)$, hematological and oncological diseases $(6.0 \%)$, cardiovascular diseases $(4.4 \%)$, infectious diseases $(1.6 \%)$ and autoimmune disorders $(1.1 \%)$.

Acceptance of preventive treatments by medically compromised children was demonstrated in Table 1 . Prevalence of medically compromised children accepting preventive treatments was $28.6 \%$. Patient with nervous system disorders (10.4\%) have highest acceptance of preventive treatments, followed by patient with specific needs $(6.04 \%)$, respiratory disorders $(3.3 \%)$, others miscellaneous diseases $(2.2 \%)$, endocrine diseases $(2.2 \%)$, cardiovascular diseases $(1.6 \%)$, gastrointestinal diseases $(1.1 \%)$, hematological and oncological diseases $(1.1 \%)$ and infectious diseases $(0.5 \%)$. Patients with autoimmune disorders show no acceptance towards preventive treatments. There is no significance in acceptance of medically compromised children with preventive treatments. (chi Square test, $\mathrm{P}=0.123$ ). (Figure 2) Medically compromised children underwent preventive treatment based on age group and gender was shown in Table 2. Prevalence of preventive treatment acceptance by medically compromised children

Figure 1. Table chart depicting distribution of medically compromised children based on medical history. $\mathrm{X}$ axis represents medical history of children and $\mathrm{Y}$ axis represents number of patients. High number of children with nervous system disorders reported to the institution.

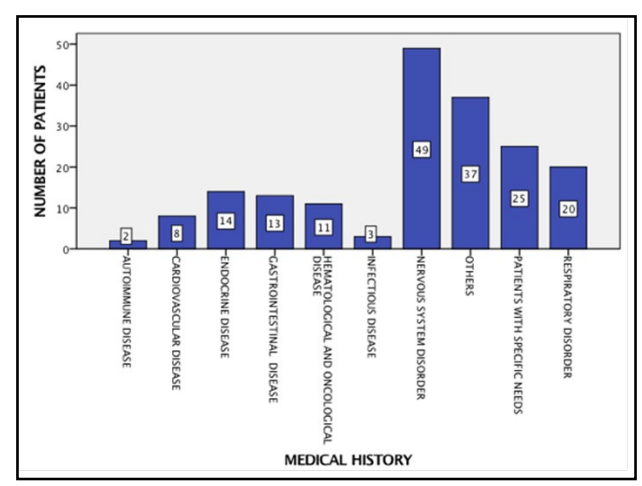


based on age group and gender was demonstrated in Figure 3 and 4. Prevalence of preventive dental treatments was illustrated in Figure 5. Pit and fissure sealants (11\%) were done for most of the medically compromised children as the preventive treatment, followed by fluoride application (8.8\%). About 8.2\% medically compromised children had done both fluoride application and pit and fissure sealants. However, $72 \%$ of medically compromised children do not undergo any preventive treatments. Association of preventive dental treatments with age group and gender was shown in Table 3. Prevalence of patients underwent preventive treatment based on age group and gender is represented in Figure 6 and 7.

Table 1. Distributions of Medically Compromised Children Undergone Preventive Treatment.

\begin{tabular}{|c|c|c|c|c|}
\hline \multirow[t]{2}{*}{ MEDICAL HISTORY } & \multicolumn{2}{|c|}{$\begin{array}{l}\text { UNDERGONE PREVEN- } \\
\text { TIVE TREATMENT }\end{array}$} & \multirow[t]{2}{*}{ TOTAL - n (\%) } & \multirow{2}{*}{$\begin{array}{l}\text { CHI SQUARE } \\
\text { TEST }\end{array}$} \\
\hline & NO - n ( $\%)$ & YES - n (\%) & & \\
\hline AUTOIMMUNE DISEASE & $2(1.1 \%)$ & $0(0 \%)$ & $2(1.1 \%)$ & \multirow{5}{*}{$\begin{array}{c}\text { Pearson chi Square }= \\
13.990\end{array}$} \\
\hline CARDIOVASCULAR DISEASE & $5(2.7 \%)$ & $3(1.6 \%)$ & $8(4.4 \%)$ & \\
\hline ENDOCRINE DISEASE & $10(5.5 \%)$ & $4(2.2 \%)$ & $14(7.7 \%)$ & \\
\hline GASTROINTESTINAL DISEASE & $11(6.0 \%)$ & $2(1.1 \%)$ & $13(7.1 \%)$ & \\
\hline $\begin{array}{l}\text { HEMATOLOGICAL AND ONCOLOGICAL } \\
\text { DISEASE }\end{array}$ & $9(4.9 \%)$ & $2(1.1 \%)$ & $11(6.0 \%)$ & \\
\hline INFECTIOUS DISEASE & $2(1.1 \%)$ & $1(0.5 \%)$ & $3(1.6 \%)$ & \multirow{5}{*}{$\mathrm{P}$ value $=0.123$} \\
\hline NERVOUS SYSTEM DISORDER & $30(16.5 \%)$ & $19(10.4 \%)$ & $49(26.9 \%)$ & \\
\hline OTHERS & $33(18.1 \%)$ & $4(2.2 \%)$ & $37(20.3 \%)$ & \\
\hline PATIENTS WITH SPECIFIC NEEDS & $14(7.7 \%)$ & $11(6.0 \%)$ & $25(13.7 \%)$ & \\
\hline RESPIRATORY DISORDER & $14(7.7 \%)$ & $6(3.3 \%)$ & $20(11.0 \%)$ & \\
\hline
\end{tabular}

Figure 2. Bar chart depicting association between acceptance of preventive treatments and medically compromised children. $\mathrm{X}$ axis represents medical history and $\mathrm{Y}$ axis represents number of children undergoing preventive treatments. Patients with nervous system disorder showed highest acceptance of preventive treatment, with no significant association seen. (Pearson chi Square value - 13.990, $P=0.123$ ).

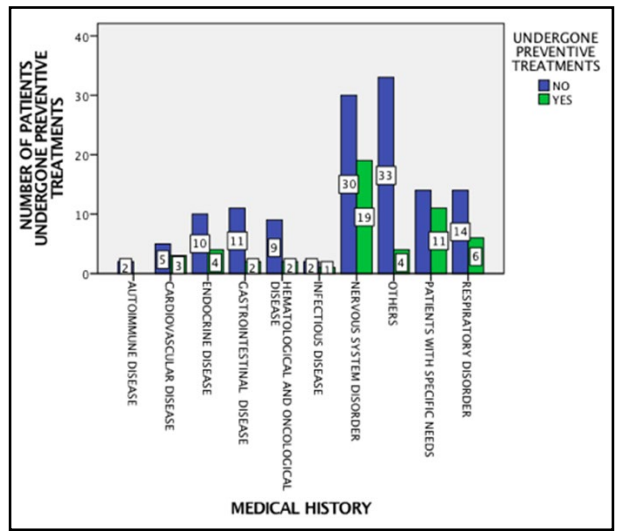

Table 2. Medically Compromised Children Undergone Preventive Treatment Based on Age Group and Gender.

\begin{tabular}{|c|c|c|c|c|}
\hline \multirow{2}{*}{$\begin{array}{l}\text { AGE } \\
\text { GROUPS }\end{array}$} & \multicolumn{2}{|c|}{$\begin{array}{c}\text { UNDERGONE PREVEN- } \\
\text { TIVE TREATMENTS }\end{array}$} & \multirow{2}{*}{$\begin{array}{l}\text { TOTAL - n } \\
(\%)\end{array}$} & \multirow[t]{2}{*}{ CHI SQUARE TEST } \\
\hline & NO - n (\%) & YES - n (\%) & & \\
\hline 1-3 YEARS & $12(6.6 \%)$ & $5(2.7 \%)$ & $17(9.3 \%)$ & Pearson chi Square $=8.315$ \\
\hline 4-6 YEARS & $21(11.5 \%)$ & $12(6.6 \%)$ & $33(18.1 \%)$ & \\
\hline 7-9 YEARS & $32(17.6 \%)$ & $14(7.7 \%)$ & $46(25.3 \%)$ & \\
\hline 10-12 YEARS & $24(13.2 \%)$ & $10(5.5 \%)$ & $34(18.7 \%)$ & \\
\hline 13-15 YEARS & $15(8.2 \%)$ & $9(4.9 \%)$ & $24(13.2 \%)$ & $\mathrm{P}$ value $=0.140$ \\
\hline 16-18 YEARS & $26(14.3 \%)$ & $2(1.1 \%)$ & $28(15.4 \%)$ & \\
\hline \multicolumn{5}{|c|}{ GENDER } \\
\hline FEMALE & $39(21.4 \%)$ & $20(11.0 \%)$ & $59(32.4 \%)$ & Pearson chi Square $=1.214$ \\
\hline MALE & $91(50 \%)$ & $32(17.6 \%)$ & $123(67.6 \%)$ & $\mathrm{P}$ value $=0.271$ \\
\hline
\end{tabular}


Figure 3. The association graph depicting medically compromised children underwent preventive treatment based on age group. $\mathrm{X}$ axis represents age groups and $\mathrm{Y}$ axis represents the number of children underwent preventive treatments. 7-9 years have highest treatment acceptance. No significance in association seen. (Pearson chi Square value $-8.315, P=0.140$ ).

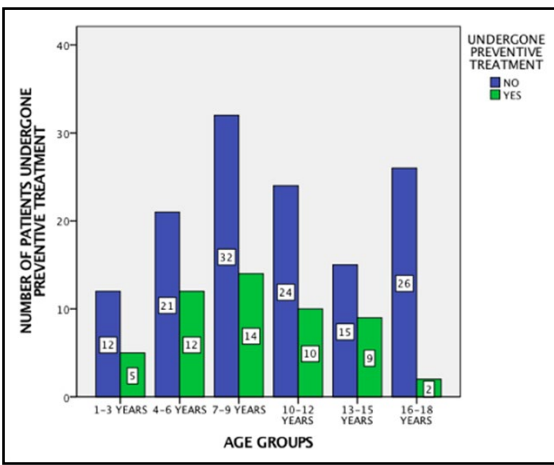

Figure 4. The association graph depicting medically compromised children underwent preventive treatment based on gender. $\mathrm{X}$ axis represents gender and $\mathrm{Y}$ axis represents number of children underwent preventive treatment. The treatment acceptance showed the highest in male. No significance in association seen. (Pearson chi Square value $-1.214, P=0.271$ )

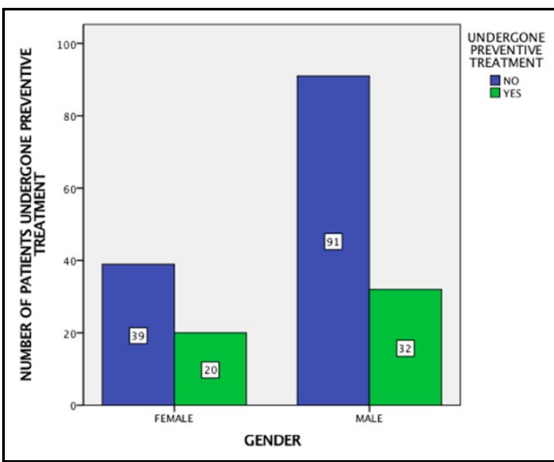

Figure 5. Bar chart depicting prevalence of preventive dental treatments. $\mathrm{X}$ axis represents preventive treatments and $\mathrm{Y}$ axis represents the number of patients. Pit and fissure sealants showed the highest prevalence.

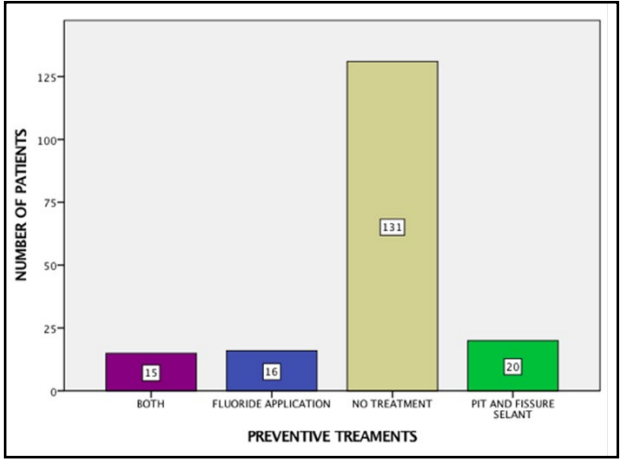

Table 3. Association of Preventive Dental Treatments with Age Group and Gender.

\begin{tabular}{|c|c|c|c|c|c|c|}
\hline \multirow[b]{2}{*}{$\begin{array}{c}\text { AGE } \\
\text { GROUPS }\end{array}$} & \multicolumn{4}{|c|}{ ACCEPTANCE TOWARDS FLUORIDE APPLICATION AND SEALANT } & \multirow[b]{2}{*}{$\begin{array}{l}\text { TOTAL n } \\
(\%)\end{array}$} & \multirow[b]{2}{*}{ CHI SQUARE TEST } \\
\hline & $\begin{array}{c}\text { FLUORIDE AP- } \\
\text { PLICATION n } \\
(\%)\end{array}$ & $\begin{array}{l}\text { PIT AND FISSURE } \\
\text { SEALANT } \mathrm{n}(\%)\end{array}$ & $\begin{array}{c}\text { BOTH ACCEPT- } \\
\text { ED n (\%) }\end{array}$ & $\begin{array}{l}\text { NOT ACCEPT- } \\
\text { ED n (\%) }\end{array}$ & & \\
\hline 1-3 YEARS & $1(0.5 \%)$ & $0(0 \%)$ & $4(2.2 \%)$ & $12(6.6 \%)$ & $17(9.3 \%)$ & $\begin{array}{c}\text { Pearson chi Square }= \\
30.724\end{array}$ \\
\hline 4-6 YEARS & $7(3.8 \%)$ & $3(1.6 \%)$ & $2(1.1 \%)$ & $21(11.5 \%)$ & $33(18.1 \%)$ & \\
\hline 7-9 YEARS & $2(1.1 \%)$ & $6(3.3 \%)$ & $3(1.6 \%)$ & $34(18.7 \%)$ & $45(24.7 \%)$ & \\
\hline $\begin{array}{c}10-12 \\
\text { YEARS } \\
\end{array}$ & $2(1.1 \%)$ & $4(2.2 \%)$ & $3(1.6 \%)$ & $25(13.7 \%)$ & $34(18.7 \%)$ & \\
\hline $\begin{array}{c}13-15 \\
\text { YEARS }\end{array}$ & $0(0 \%)$ & $6(3.3 \%)$ & $3(1.6 \%)$ & $15(8.2 \%)$ & $24(13.2 \%)$ & \\
\hline $\begin{array}{c}16-18 \\
\text { YEARS }\end{array}$ & $2(1.1 \%)$ & $0(0 \%)$ & $0(0 \%)$ & $26(14.3 \%)$ & $28(15.4 \%)$ & $\mathrm{P}$ value $=0.010^{*}$ \\
\hline \multicolumn{7}{|c|}{ GENDER } \\
\hline FEMALE & $4(2.2 \%)$ & $11(6.0 \%)$ & $4(2.2 \%)$ & $40(22.0 \%)$ & $59(32.4 \%)$ & Pearson chi Square $=6.263$ \\
\hline MALE & $10(5.5 \%)$ & $8(4.4 \%)$ & $11(6.0 \%)$ & $93(51.1 \%)$ & $\begin{array}{c}122 \\
(67.0 \%)\end{array}$ & $P$ value $=0.100$ \\
\hline
\end{tabular}


Figure 6. The association graph depicting association of preventive dental treatments and age group. $\mathrm{X}$ axis represents age groups and $\mathrm{Y}$ axis represents preventive treatments. Fluoride application was highly prevalent in 4-6 years and pit and fissure sealant in 7-9 years and 13-15 years. Pearson chi square value $-30.724, P=0.010(<0.05)$, statistically significant.

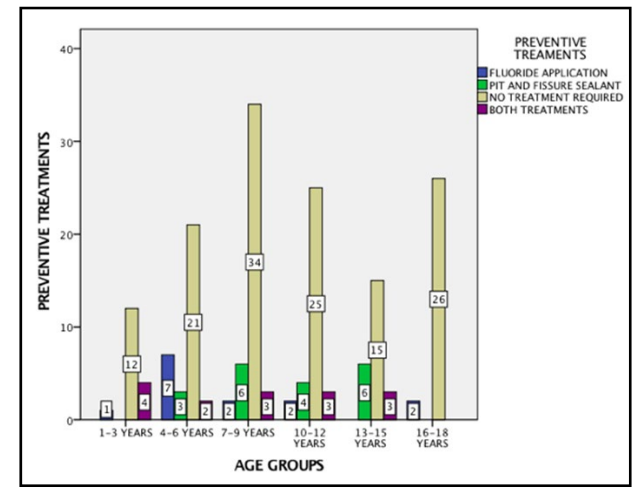

Figure 7. The association graph depicting preference of preventive dental treatments and gender. $\mathbf{X}$ axis represents the gender and $\mathrm{Y}$ axis represents preventive treatments. Highest number of patients underwent both treatments in males and pit and fissure sealant treatment in females. No significance association (Pearson chi Square value $-6.263, P=0.100$ ).

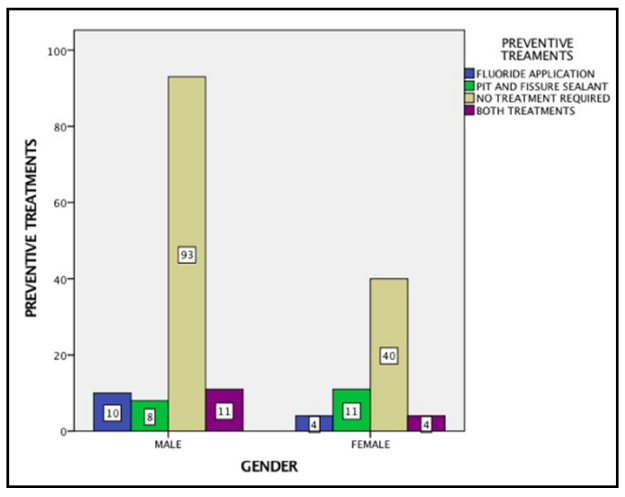

\section{Discussion}

Comprehensive dental care for medically compromised and special children requires full attention on their underlying systemic conditions in consideration to association of their medical conditions with specific oral manifestations of a systemic disease. Furthermore, there is also potential risk for the patients to develop oral diseases due to adverse effects of their medication and also due to decrease of host resistance of the body against the oral infections [8] in particular, children with mental, developmental or physical disabilities, including systemically unhealthy children. Any dental pain or infections in oral cavities may threaten their day to day activity and quality of their life, as they are more vulnerable and susceptible to develop higher risk of oral diseases. [6, 77. In addition to this, growth abnormalities and patients' medical condition also may adversely affect their oral health [15]. Also reduced nutritional intake due to systemic condition may lead to malnutrition of the child [16], resulting in progressions of oral disease. Thus, preventive dental measures are essential in medically compromised and special children in avoiding dental decay which can eliminate future pain and invasive dental treatments.

In this study, we evaluated the acceptance towards preventive dental treatment, with a view to showcase the importance of oral health care among the medically compromised children and special children. In our study, the overall prevalence in preference towards preventive dental treatment was found be very less $(28.6 \%)$. Though less number of patients reported, very few patients preferred preventive treatments. The number of patients reported to the institution was lower in comparison to studies reported by
Bensouda Sana et al, Cetinguc A et al and Brown et al. [6-8]. this may be due to geographic location. The preventive procedures in children with special needs or disabled children are required mandate due to limited cooperation and lack of manual dexterity among them which causes poor oral hygiene in those individuals. Higher acceptance was seen among patients with nervous system disorder $(10.4 \%)$ followed by patients with special health needs $(6 \%)$. In case of children presenting with autoimmune disorder, none preferred preventive treatment and other systemic diseases, very less preference was noticed. Thus, this showed that the majority of medically compromised and children with special needs didn't prefer any preventive treatments. This finding was in line with a article reported by Bensouda Sana et al, Cetinguc A et al and Brown et al, where in their study most of the reported patients were not willing to undergo any recommended preventive treatments by their dentists [6-8].

In addition to this, though patients visited Pedodontists, very less underwent preventive treatment and most of the patients did not undergo any preventive dental procedures. However, in a study reported by Romana et al, instead of undergoing preventive treatments, most of the medically compromised children preferred to undergo dental treatments focusing on the management of permanent teeth [17]. In consensus with their medical conditions, these children are prone to develop dental caries and have association with other additional risk factors other than poor oral hygiene which emphasizes the importance of preventive care such as pit and fissure sealant and fluoride application. Hence, having regular dental checkups can promote oral health, reducing the risk of accumulation of bacteria and plaque retention on the teeth, thereby reducing the risk of dental caries, gingivitis and other oral 
diseases [7, 12]. Furthermore, early loss of primary dentition can also be avoided, as it can cause space loss for the eruption of permanent teeth $[4,5]$.

In our study, more preference for preventive treatment was found among 7-9 year age group, Despite various advances in the preventive methods against dental caries, it still remains as a potent threat for infants and children [18]. It is important to implement preventive treatment in early age for early detection which will prevent progression of oral diseases into worse state. Therefore, it will help to reduce the percentage of untreated teeth as well as dental caries [7, 19]. Another study, reported by Romana et al stated that during adolescent stage it is important stage to have good oral care, as during this phase permanent dentition begins to erupt [17]. Hence, medically compromised children who have high caries risk should have regular dental check-ups every 3-6 months even if they don't have any problems concerning their teeth [20]. Also as AAPD states placement of sealants on primary molars would aid in preventing caries development and progression as well as reduces number of cariogenic bacteria, hence forth sealants are recommended over 3 years of age till adolescents.

In this study, pit and fissure sealants showed the highest prevalence of preference compared to fluoride application. Based on age group and gender, overall distribution of preference was seen more in pit and fissure sealant than the fluoride application. Based on study reported by Azarpazhooh A et al, pit and fissure sealants were used as prevention strategies in caries risk pediatric patients [21]. This finding was supported by John $\mathrm{T}$ et al, where in his study majority of pediatric participants showed reduction in development of new caries with the application of sealants [22]. Fluoride application also a part of comprehensive tooth decay prevention [23-25]. Optimal quantities of fluoride will help in caries prevention by deposition of calcium fluoride crystals which is more resistant to demineralization [26]. Thus, optimum level of exposure to fluoride is safe $[21,22]$. Comprehensive health education programs are recommended in educating parents and care takers [27], who lack of awareness on preventive treatments especially about sealants and fluoride application which is not optional but recommended both. Knowledge on oral hygiene should be implemented in early age for medically compromised and special children.

\section{Conclusion}

Within the limitation of study, it can be concluded that:

1. The prevalence of medically compromised children preferring preventive dental treatment was relatively low which may be due to lack of awareness among medically compromised and special children parents in receiving preventive procedures.

2. In regards to their medical condition, most of the medical conditions didn't prefer preventive treatment except patients with nervous system disorder who preferred for preventive procedures. 3. Age group of 7-9 years showed the highest preference towards treatment acceptance, with male predilection.

4. Overall, pit and fissure sealant was the most preferred preventive treatment than fluoride application.

Thus, a proper health education and motivation tools are required in improving their awareness and knowledge towards preventive dentistry. Also preventive dentistry programs should be undertaken in future involving parents, teachers, and specialized dental teams to look after the oral health needs of the medically compromised and disabled population.

\section{Future Scope}

The further studies need to be done which focuses on the correlation between parent's economic status, literacy rates and the possible reason for not accepting the treatment as a next step towards understanding the patient's point of view and possible methods to combat the problem to prevent future complications. Also it becomes the primary responsibility of the dental health care professionals to educate the patient, and their parents by creating awareness about preventive measures and its benefits through health education programs and dental campaigns. This will help to understand the importance of preventive measures for medically compromised and special children.

\section{References}

[1]. Gurunathan D, Shanmugaavel AK. Dental neglect among children in Chennai. J Indian Soc Pedod Prev Dent. 2016 Oct 1;34(4):364-9.

[2]. Ravikumar D, Jeevanandan G, Subramanian EM. Evaluation of knowledge among general dentists in treatment of traumatic injuries in primary teeth: A cross-sectional questionnaire study. Eur J Dent. 2017 Apr;11(02):232-7.

[3]. Panchal V, Jeevanandan G, Subramanian E. Comparison of instrumentation time and obturation quality between hand $\mathrm{K}$-file, $\mathrm{H}$-files, and rotary Kedo-S in root canal treatment of primary teeth: A randomized controlled trial. J Indian Soc Pedod Prev Dent. 2019 Jan-Mar;37(1):75-79.Pubmed PMID: 30804311.

[4]. Govindaraju L, Jeevanandan G, Subramanian EMG. Comparison of quality of obturation and instrumentation time using hand files and two rotary file systems in primary molars: A single-blinded randomized controlled trial. Eur J Dent. 2017 Jul-Sep;11(3):376-379.Pubmed PMID: 28932150.

[5]. Jeevanandan G. Kedo-S Paediatric Rotary Files for Root Canal Preparation in Primary Teeth - Case Report. J Clin Diagn Res. 2017 Mar;11(3):ZR03ZR05.Pubmed PMID: 28511532.

[6]. Sana B, Mouna E, Zineb A, Soukaina EM, Sarah B, Mouna H, et al. Profile of Medically Compromised Children Attending the Pediatric Dentistry Department of the Casablanca Dental Consultation and Treatment Center.Int. J. Dent. Med.2019;5(1):35.

[7]. Brown A. Caries prevalence and treatment needs of healthy and medically compromised children at a tertiary care institution in Saudi Arabia. East Mediterr Health J. 2009 Mar-Apr;15(2):378-86.Pubmed PMID: 19554985.

[8]. Ayflegül ÇE, NGÜÇ D, Meryem TE, ÇEK D. Oral Health Status of Medically Compromised Children Referred for Dental Consultations: A Retrospective Study.

[9]. Oewen RR. The role of dentists on medically compromised children's oral and dental prophylaxis in Hospital. J Dent. 2008 Dec 1;41(4):160-3.

[10]. Govindaraju L, Gurunathan D. Effectiveness of Chewable Tooth Brush in Children-A Prospective Clinical Study. J Clin Diagn Res. 2017 Mar;11(3):ZC31-ZC34.Pubmed PMID: 28511505.

[11]. Subramanyam D, Gurunathan D, Gaayathri R, Vishnu Priya V. Comparative evaluation of salivary malondialdehyde levels as a marker of lipid peroxidation in early childhood caries. Eur J Dent. 2018 Jan-Mar;12(1):67-70. Pubmed PMID: 29657527.

[12]. Naaman R, El-Housseiny AA, Alamoudi N. The use of pit and fissure sealants-A literature review. J Dent. 2017 Dec;5(4):34.

[13]. Jeevanandan G, Govindaraju L. Clinical comparison of Kedo-S paediatric rotary files vs manual instrumentation for root canal preparation in primary molars: a double blinded randomised clinical trial. Eur Arch Paediatr Dent. 2018 Aug;19(4):273-278.Pubmed PMID: 30003514.

[14]. Govindaraju L, Jeevanandan G, Subramanian E. Clinical Evaluation of Quality of Obturation and Instrumentation Time using Two Modified Rotary File Systems with Manual Instrumentation in Primary Teeth. J Clin Diagn Res. 2017 Sep;11(9):ZC55-ZC58.Pubmed PMID: 29207834.

[15]. Dharmani CK. Management of children with special health care needs (SHCN) in the dental office. J. Med. Soc. 2018 Jan 1;32(1):1.

[16]. Christabel SL, Gurunathan D. Prevalence of type of frenal attachment and morphology of frenum in children, Chennai, Tamil Nadu. World J Dent. 
2015 Oct;6(4):203-7.

[17]. Koberova Ivancakova R, Suchanek J, Kovacsova F, Cermakova E, Merglova V. The Analysis of Dental Treatment under General Anaesthesia in Medically Compromised and Healthy Children. Int. J. Environ. Res. Public Health. 2019 Jan;16(14):2528.

[18]. Lakshmanan L, Mani G, Jeevanandan G. Assessing the quality of obturation and instrumentation time using Kedo-S files, Reciprocating files and Hand K-files. Braz. Dent. Sci. 2020;23.

[19]. Packiri S, Gurunathan D, Selvarasu K. Management of paediatric oral ranula: a systematic review. J Clin Diagn Res. 2017 Sep;11(9):ZE06-9.

[20]. Paperpile [Internet]. [cited 2020 Jun 18]. Available from: https://paperpile. com/app/p/0cbac74f-e8a3-0b2e-bce6-a0a90ba7ea68

[21]. Azarpazhooh A, Main PA. Pit and fissure sealants in the prevention of dental caries in children and adolescents: a systematic review. J Can Dent Assoc. 2008 Mar 1;74(2):171-7.

[22]. Wright JT, Tampi MP, Graham L, Estrich C, Crall JJ, Fontana M, et al. Sealants for preventing and arresting pit-and-fissure occlusal caries in primary and permanent molars. Pediatr Dent. 2016 Jul 15;38(4):282-308.

[23]. Chi DL. Parent Refusal of Topical Fluoride for Their Children: Clinical Strategies and Future Research Priorities to Improve Evidence-Based Pediatric Dental Practice. Dent Clin North Am. 2017 Jul;61(3):607-617.Pubmed PMID: 28577640.

[24]. Da Fonseca MA. Dental care of the pediatric cancer patient. Pediatr Dent. 2004 Jan 1;26(1):53-7.

[25]. Ramakrishnan M, Bhurki M. Fluoride, Fluoridated Toothpaste Efficacy And Its Safety In Children-Review. Int. J. Pharm. Res.. 2018 Oct 1;10(04):10914.

[26]. Somasundaram S, Ravi K, Rajapandian K, Gurunathan D. Fluoride Content of Bottled Drinking Water in Chennai, Tamilnadu. J Clin Diagn Res. 2015 Oct;9(10):ZC32-4.Pubmed PMID: 26557612.

[27]. Govindaraju L, Jeevanandan G, Subramanian EM. Knowledge and practice of rotary instrumentation in primary teeth among indian dentists: A questionnaire survey. J Int Oral Health. 2017 Mar 1;9(2):45. 